\title{
PERILAKU GESEK BATU CANDI DENGAN TANAH PASIR
}

Oleh

Iskandar M. Siregar, S.Si

\section{Balai Konservasi Peninggalan Borobudur}

Runtuhnya lereng atau yang sering kita kenal sebagai tanah longsor dapat terjadi apabila batas stabilitas ijin tanah terlampaui. Apabila keruntuhan lereng terjadi, maka sekokoh apapun suatu bangunan akan ikut runtuh juga. Untuk itu evaluasi mengenai stabilitas lereng sangat diperlukan, apalagi untuk bangunan benda cagar budaya seperti Candi Borobudur. Sifat mekanika tanah yang paling penting dalam evaluasi stabilitas lereng adalah kuat geser tanah. Sehingga penelitian pendahuluan tentang kekuatan geser tanah sangat diperlukan.

Penelitian dilakukan untuk menghitung besarnya parameter kuat geser, yaitu nilai kohesi (c) dan sudut gesek internal $(\Phi)$ antara batu candi dengan tanah pasir yang merupakan tanah fondasi Candi Borobudur. Nilai kuat geser ini selanjutnya dapat digunakan untuk analisis stabilitas tanah Candi Borobudur.

Dari hasil uji geser langsung diketahui nilai kohesi (c) antara batu dengan tanah pasir lempungan $0,0064 \mathrm{~kg} / \mathrm{cm}^{2}$, antara batu dengan tanah pasir 0,0177 $\mathrm{kg} / \mathrm{cm}^{2}$, dan antara batu dengan batu $0,0025 \mathrm{~kg} / \mathrm{cm}$. Sementara itu nilai sudut gesek internal 0 antara batu dengan tanah pasir lempungan $34,96^{\circ}$, antara batu dengan tanah pasir $35,47^{\circ}$, dan antara batu dengan batu $40,15^{\circ}$.

\section{PENDAHULUAN}

\subsection{Latar Belakang}

Candi Borobudur dibangun di atas tanah bukit yang diratakan dan sebagian merupakan tanah urug. Bangunan candi telah mengalami 2 (dua) kali pemugaran, yang pertama oleh Van Erph sekitar tahun 1907, meliputi perbaikan pada tingkat Rupadhatu dengan meratakan lantai lorong sementara dindingnya dibiarkan apa adanya, dinding yang miring diperkuat dengan kayu penahan. Pemugaran kedua dilakukan pada tahun 1973-1983 yang meliputi pekerjaan struktur, arsitektur, dan konservasi batu candi. Dalam pemugaran kedua ini dilakukan pembongkaran dinding lorong I sampai pagar langkan tingkat $\mathrm{V}$, pada setiap lorong dipasang slab beton dengan bentuk melingkar mengikuti profil dinding.

Kajian ini dilakukan untuk mengetahui kondisi geser batu candi dengan tanah dasar baik akibat beban statis maupun beban dinamis yang terjadi. Sebagian besar batu Candi Borobudur terletak di atas tanah urug yang merupakan lempung pasiran dan pasir dengan ketebalan lapisan berkisar antara $0,5-8,5$ meter.

\subsection{Maksud dan Tujuan}

Penelitian bermaksud untuk menguji kuat geser beban statis antara batu candi dengan tanah pasir dengan metode pemodelan di laboratorium. Tujuan penelitian ini adalah untuk mengetahui besarnya parameter kuat geser, yaitu nilai kohesi (c) dan sudut gesek internal $(\Phi)$ antara batu candi dengan tanah pasir yang merupakan tanah fondasi Candi Borobudur. Parameter yang diperoleh dari pengujian kuat geser ini selanjutnya dapat digunakan untuk analisis stabilitas tanah Candi Borobudur. Di samping itu dihitung juga berat jenis (specific gravity) sampel.

\section{TINJAUAN PUSTAKA}

Batuan dianggap sebagai suatu agregat alam dan butiran mineral yang dilekatkan oleh gaya kohesif yang kuat dan permanen. Sedangkan tanah dianggap sebagai suatu agregat alam dari butiran mineral, dengan atau tanpa konstituen organik, yang dapat dipisahkan dengan cara mekanis ringan seperti pengadukan dalam air (Peck, Hanson, and Thornburn, 1996). Defenisi ini sangat jelas dan mudah dimengerti, namun demikian dalam kenyataannya tidak ada perbedaan yang mencolok antara batuan dan tanah. Batuan yang paling kuat dan keraspun dapat dilemahkan melalui proses pelapukan oleh cuaca, dan beberapa tanah yang mengalami pengerasan dapat mempunyai kekuatan setara dengan batuan yang mengalami pelapukan.

Istilah utama yang umum dipakai untuk menyatakan tanah adalah kerikil, pasir, lanau, dan lempung. Sebagian besar tanah alam terdiri dari campuran dua atau lebih konstituen (komponen) ini, dan banyak tanah yang mengandung campuran material organik pada keadaan sebagian atau sepenuhnya lapuk. Campuran ini diberi nama menurut komponen yang paling berpengaruh terhadap perilakunya, sedangkan komponen yang lain ditunjukkan sebagai kata sifat. Misalnya lempungberlanau berarti tanah tersebut mempunyai sifat-sifat dominan lempung tapi mengandung sejumlah lanau, dan lanau-organik terutama berupa bahan mineral berukuran lanau tetapi mengandung sejumlah material organik.

Kerikil dan pasir dikenal sebagai tanah berbutir kasar, sedangkan lanau dan lempung sebagai tanah berbutir halus. Perbedaann ini didasarkan atas apakah partikel-partikel individunya dapat dibedakan dengan 
mata telanjang. Partikel yang mempunyai diameter lebih besar dari sekitar $5 \mathrm{~mm}$ diklasifikasikan sebagai kerikil. Tetapi, jika diameternya melebihi sekitar $200 \mathrm{~mm}$ (8 inchi) biasanya disebut dengan istilah batu besar (Peck, Hanson, and Thornburn, 1996).

\subsection{Perilaku Geser Pada Massa Butiran Ideal}

Seperti material teknik lain, tanah mengalami penyusutan volume jika menderita tekanan merata di sekelilingnya. Jika menerima tegangan geser tanah akan mengalami distorsi; dan apabila distorsi yang terjadi cukup besar maka partikelnya akan terpeleset satu sama lain dan tanah dikatakan gagal dalam geser. Karakteristik kekuatan geser tanah merupakan hal yang sangat penting untuk mengetahui permasalahan tanah fondasi.

Jika suatu susunan partikel kokoh yang semula lepas menjadi rapat dan susunan yang rapat menjadi lebih jarang pada saat diberi tegangan geser merupakan karakteristik dasar dari sekumpulan partikel-partikel yang memiliki butiran seragam (equideminsional) atau kurang seragam yang cukup kuat untuk tidak hancur. Pasir dan kerikil memiliki karakteristik yang mirip dengan perilaku ini. Sementara itu lempung lunak akan cenderung mengalami penyusutan volume jika ada tegangan geser yang bekerja, sedangkan lempung keras cenderung akan mengembang. Oleh karena itu, perilaku lempung dapat dikatakan analog dengan perilaku pasir (Peck, Hanson, and Thornburn, 1996).

\subsection{Kuat GeserTanah}

Kuat geser untuk setiap jenis tanah terutama sekali tergantung pada nilai tekanan pori pada saat akan terjadi keruntuhan geser. Tekanan pori yang berlebihan mungkin disebabkan oleh tegangan-tegangan yang bekerja langsung dalam tanah dan oleh kecenderungan berubahnya volume tanah selama terjadinya tegangan geser. Sementara akibat adanya drainase maka tekanan pori yang berlebihan cenderung untuk menghambur, sehingga kuat geser yang dapat dihasilkan di lapangan tergantung pada besarnya nilai permeabilitas dan dimensi dari tanah yang dipengaruhi oleh tegangan-tegangan geser. Kuat geser tersebut juga tergantung kecepatan saat pengerjaan tegangan. Suatu perubahan yang sangat lambat dalam pengerjaan tegangan pada suatu massa tanah dengan permeabilitas rendah tidak akan menghasilkan tekanan pori yang lebih besar dibanding pengerjaan tegangan secara cepat pada tanah dengan permeabilitas tinggi. Pertimbangan-pertimbangan ini memberikan sebuah dasar untuk memperkirakan kekuatan geser pada permasalahan-permasalahan praktis atau untuk memilih langkah-langkah pengujian yang sesuai dan berkaitan dengan masalah yang ada.

Parameter kuat geser tanah digunakan untuk analisis daya dukung tanah, stabilitas lereng, dan gaya dorong dinding penahan tanah. Kuat geser adalah gaya perlawanan yang dilakukan oleh butir-butir tanah terhadap desakan dan tarikan (Hardiyatmo, 1994). Nilai kuat geser sebanding dengan tegangan normal/vertikal yang bekerja pada bidang geser. Kuat geser dipengaruhi pula oleh gaya kohesi tanah yang bergantung pada jenis tanah dan kepadatannya.

Nilai kuat geser merupakan fungsi dari gaya normal, dituliskan dengan rumus:

$$
\mathrm{t}=c+\sigma \tan \Phi
$$

Persamaan (2.1) disebut kriteria keruntuhan atau kegagalan Mohr-Coulomb. Menurut Terzaghi (1952) yang ditulis dalam Hardiyatmo (1994), persamaan di atas perlu diperbaiki dengan memasukkan pengaruh tegangan efektif sebagai akibat pengaruh tegangan air pori sehingga persamaan (2.1) menjadi

$$
\mathrm{t}=\mathrm{i}^{\prime}+(\sigma-\mathrm{u}) \tan \Phi^{\prime}(2.2)
$$

jika $\quad \sigma^{\prime}=(\sigma-\mathrm{u})$

maka $\mathrm{t}=c^{\prime}+\sigma^{\prime} \tan \Phi^{\prime}(2.3)$

dimana $\mathrm{t}=$ Kuatgeser $\left(\mathrm{kg} / \mathrm{cm}^{2}\right.$

$\mathrm{c}=$ gaya kohesi $\left(\mathrm{kg} / \mathrm{cm}^{2}\right)$

$\sigma=$ tegangan normal pada bidang runtuh $\left(\mathrm{kg} / \mathrm{cm}^{2}\right)$

$\Phi=$ sudut gesek internal $\left({ }^{\circ}\right)$

$\mathrm{c}^{\prime}=$ kohesi tanah efektif $\left(\mathrm{kg} / \mathrm{cm}^{2}\right)$

$\sigma^{\prime}=$ tegangan normal efektif $\left(\mathrm{kg} / \mathrm{cm}^{2}\right)$

$\Phi^{\prime}=$ sudut gesek efektif $\left({ }^{\circ}\right)$

$\mathrm{U}=$ tekanan airpori $\left(\mathrm{kg} / \mathrm{cm}^{2}\right)$

\section{METODE PENELITIAN}

\subsection{Peralatan dan Bahan Penelitian}

Peralatan yang dipergunakan untuk kajian ini adalah:

a. Satu unit alat uji geser langsung yang tersedia di Laboratorium Makanika Tanah Jurusan Teknik Sipil, Fakultas Teknik, Universitas Gadjah Mada Yogyakarta. Alat tersebut terdiri dari:

1) kotakgeser persegi dengan ukuran $100 \mathrm{~mm} \times 100$ $\mathrm{mm}$,

2) beban,

3) cincin beban,

4) arloji beban geser, 
5) arloji pengukur penurunan benda uji,

6) arloji pengukur regangan penggeseran.

b. Stopwatch.

c. Alat-alat penyiapan benda uji yaitu kuas, spatula, dan kain lap.

Bahan yang dipergunakan pada penelitian ini
Gambar 3.1

Alat dan sampel untuk menguji

kuat geser langsung

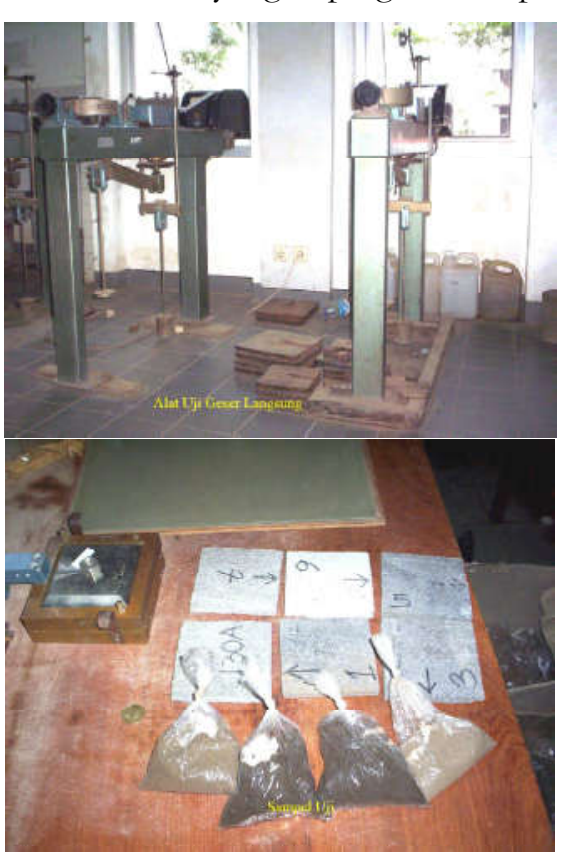

yang ada di sekitar Candi Borobudur. adalah sampel tanah dan batu. Sampel tanah diambil dari halaman Barat C $\quad$ a $n$ d $\quad$ i Borobudur, yaitu tanah yang berada dekat sekali dengan batu candi. Tanah ini merupakan tanah lapisan horison A ( $\mathrm{S}$ a mpurno, $\left.\begin{array}{lllll}1 & 9 & 6 & 9\end{array}\right)$. Sementara itu sampel batu diambil dan dipilih dari batu-batu lepas

Untuk sampel tanah terdiri dari 2 jenis yaitu tanah pasir dan tanah pasir sedikit lempungan yang diambil dari halaman Candi Borobudur sebelah Barat. Sampel batu digergaii sehingga berbentuk persegi dengan ukuran 100 $\mathrm{mm} \times 100 \mathrm{~mm}$ dan ketebalan $10 \mathrm{~mm}$, salah satu sisi permukaan sampel batu dipertahankan keaslian, karena permukaan inilah yang akan bergesekan dengan tanah dan diharapkan dapat mewakili keadaan yang sesungguhnya terjadi pada fondasi Candi Borobudur. Sampel batu yang digunakan untuk pengujian geser langsung ini berjumlah 90 buah dengan rincian sebagai berikut:

a. 30 (tiga puluh) batu untuk pengujian geser langsung dengan tanah pasir dan tanah pasir lempungan.

b. 60 (enam puluh) batu untuk pengujian geser langsung antara batu dengan batu.

\subsection{Prosedur Penelitian}

Penelitian dimulai dengan survai untuk mencari dan menentukan sampel batu dan tanah pasir yang paling sesuai dengan tujuan penelitian serta kondisi lapangan yang sebenarnya. Pengujian sampel dimulai dengan tahapan sebagai berikut: a. Pengujian dibagi 3 bagian:

1) Uji geser langsung batu dengan tanah pasir lempungan.

2) Uji geser langsung batu dengan tanah pasir.

3) Ujigeser langsung batu dengan batu.

b. Menyiapkan benda uji

1) Disiapkan 30 batu, tanah pasir lempungan, dan tanah pasir, tiap 10 pasang sampel diberi tegangan normal $0,25 \mathrm{~kg} / \mathrm{cm}^{2}, 0,50 \mathrm{~kg} / \mathrm{cm}^{2}$ dan $0,75 \mathrm{~kg} / \mathrm{cm}^{2}$.

2) Disiapkan 60 batu dengan batu, tiap 10 pasang sampel diberi tegangan normal $0,25 \mathrm{~kg} / \mathrm{cm}^{2}, 0,50$ $\mathrm{kg} / \mathrm{cm}^{2}$ dan $0,75 \mathrm{~kg} / \mathrm{cm}^{2}$.

c. Memasang benda uji ke alat geser langsung

1) Kedua bagian kotak geser disatukan dengan sekrup pengunci yang ada.

2) Bagian-bagian kotak geser disusun dari yang paling bawah yaitu alas dan pelat bergigi di atasnya.

3) Tanah uji dimasukkan ke dalam kotak geser dan dipadatkan sampai ketebalan sekitar $1 \mathrm{~cm}$. Kepadatan untuk tiap percobaan diusahakan sama.

4) Sampel batu dimasukkan sedemikian sehingga kotak geser dapat bergeser tanpa tersangkut sampel batu.

5) Plat bergigi yang kedua dipasang di atas sampel batu.

6) Paling atas dipasang penerus beban secara sentris.

d. Perlengkapan pembebanan diatur, arloji pembaca beban dan arloji penurunan dalam posisi nol.

e. Beban diberikan sehingga sampel uji akan menerima tegangan normal sebesar yang telah ditentukan.

f. Sampel uji dibiarkan sejenak setelah beban diterapkan agar terkonsolidasi. Besar penurunan yang terbaca pada arloji penurunan dicatat sebagai penurunan awal.

g. Setelah tanah terkonsolidasi, kedua sekrup pengunci dibuka dan kedua sekrup peregang diputar bersamasama agar kotak geser meregang. Setelah kotak geser teregang, kedua sekrup peregang tersebut dilepas.

h. Penggeseran dilakukan dengan kecepatan 1,06 $\mathrm{mm} /$ menit.

i. Pengamatan dan pencatatan dilakukan tiap 15 detik untuk 1 menit pertama dan tiap 30 detik untuk menit berikutnya sampai menit ke 10 .

j. Setelah tergeser kurang lebih 10\%, sampel uji dikeluarkan dari kotak geser.

k. Sampel uji diberi label dan juga arah penggeserannya. 


\section{HASIL DAN PEMBAHASAN}

\subsection{Uji Geser Langsung}

Dari perhitungan, nilai tegangan normal dan tegangan geser maksimum di plotkan kedalam grafik kemudian dicari regresi dan hubungan antara keduanya, sehingga didapatkan nilai kohesi tanah dan sudut gesek internal.

Tabel 4.1 menunjukkan hasil uji geser langsung antara batu dengan tanah pasir lempungan, antara batu dengan tanah pasir, dan antara batu dengan batu. Setiap sampel diuji dengan memberikan 3 (tiga) macam tegangan normal, yaitu $0,25 \mathrm{~kg} / \mathrm{cm}^{2}, 0,50 \mathrm{~kg} / \mathrm{cm}^{2}$, dan $0,75 \mathrm{~kg} / \mathrm{cm}^{2}$. Setelah dilakukan perhitungan diperoleh nilai tegangan geser maksimum untuk setiap tegangan normal yang diberikan dan setiap jenis sampel yang diuji. Tegangan geser maksimum kemudian diolah dengan analisis regresi.

Tabel 4.2 adalah rekapitulasi analisis regresi hasil uji geser langsung seperti yang telah ditunjukan pada Tabel 4.1. Dari hasil nilai tegangan normal dan tegangan geser maksimum dibuat grafik regresi uji geser langsung. Dari grafik dapat ditentukan persamaan yang akan digunakan untuk menghitung paramater yang dicari. Misalnya dari hasil uji geser langsung antara batu dengan tanah pasir lempungan diperoleh persamaan:

$$
\mathrm{Y}=0,6992 \mathrm{x}+0,064 \text {. }
$$

0,064 sebagai konstanta pada persamaan di atas merupakan nilai kohesi (c) antara batu dengan tanah pasir lempungan. Sedangkan sudut gesek internal $(\Phi)$ dapat dihitung dari arc tangen koefisien garis $(\mathrm{m}=0,6992)$, yaitu $34,96^{\circ}$.

Dari ketiga macam uji geser langsung dengan tiga macam tegangan normal diperoleh hasil sebagai berikut.

a. Uji geser langsung antara batu dengan tanah pasir lempungan
1) Nilai kohesi(c):
$0,0064 \mathrm{~kg} / \mathrm{cm}^{2} \approx 0,00 \mathrm{~kg} / \mathrm{cm}^{2}$
2) Sudut gesek internal $(\Phi)$ : $34,96^{\circ} \approx 35,0^{\circ}$

b. Uji geser langsung antara batu dengan tanah pasir

1) Nilai kohesi (c) : $0,0177 \mathrm{~kg} / \mathrm{cm}^{2} \approx 0,00 \mathrm{~kg} / \mathrm{cm}^{2}$

2) Sudutgesek internal $(\Phi)$ : $35,47^{\circ} \approx 35,5^{\circ}$

c. Uji geser langsung antara batu dengan batu

1) Nilai kohesi (c): $0,0025 \mathrm{~kg} / \mathrm{cm}^{2} \approx 0,00 \mathrm{~kg} / \mathrm{cm}^{2}$

2) Sudut gesek internal $(\Phi)$ : $40,15^{\circ} \approx 40,0^{\circ}$

Nilai kohesi (c) untuk ketiga jenis pengujiaan di atas hampir sama dengan 0 (nol) atau nilainya dapat diabaikan, sementara itu untuk nilai sudut gesek internal 0 masih cukup baik. Nilai ideal sudut gesek internal untuk jenis tanah yang diteliti adalah $30^{\circ}-$ $40^{\circ}$.

Jika suatu lereng akan mengalami keruntuhan, maka tanah akan melawan gaya geser tersebut dengan meningkatkan kekuatan gesernya. Melalui mekanisme lekatan dan gesekan membuat tanah menjadi kompak dan menyatu. Hubungan yang saling mengunci antara batu candi dengan tanah dasarnya akan menambah sumbangan perlawanan terhadap gaya geser tersebut.

Uji geser langsung merupakan salah satu pengujian untuk mengetahui parameter kuat geser tanah. Dengan pengujian ini diperoleh keluaran berupa nilai kohesi tanah (c), dan sudut gesek internal tanah 0. Nilai kohesi tanah berpengaruh pada mekanisme lekatan sedang sudut gesek internal berpengaruh pada mekanisme gesekannya.

\subsection{Berat jenis Tanah}

Pada penelitian ini juga dilakukan pengujian untuk menentukan berat jenis (specific gravity) sampel tanah. Sampel tanah pasir lempungan memiliki berat jenis antara 2,70-2,77 dan tanah pasir antara 2,80-2,90.

\section{PENUTUP}

Kajian ini bukanlah merupakan kajian yang menghasilkan data-data yang langsung dapat digunakan dalam menentukan kondisi Candi Borobudur. Akan tetapi hasil kajian ini dapat digunakan lebih lanjut untuk kajian stabilitas struktur Candi Borobudur terhadap gempa dengan memasukkan parameter-parameter yang telah dihitung dari kajian ini.

\section{DAFTAR PUSTAKA}

Braja, M. Das, 1985, Principles of Geothecnical Engineering, PWS Publishers.

Hardiyatmo, H.C., 1992, Mekanika Tanah 1, Penerbit Pustaka Utama Gramedia, Jakarta.

,1994, Mekanika Tanah 2, Penerbit Pustaka Utama Gramedia, Jakarta.

Peck, B.R., W.E. Hanson, and T.H. Thornburn, 1996, Teknik Fondasi, Terjemahan Muslikh, Gadjah Mada University Press, Yogyakarta.

Sampurno, 1969, Penelitian Tanah Dasar Tjandi Borobudur, Pelita Borobudur Seri B No. 3, Departemen Pendidikan dan Kebudayaan, Jakarta.

Wesley, L.D., 1977, Mekanika Tanah, Badan Penerbit Pekerjaan Umum, Jakarta. 